\title{
Peace Issues
}

\section{Editor's Note:}

During the 1987 meetings of the association of Behavior Analysis, a symposium was held entitles "War, Peace, and Behavior Analysis". A truly distinguished contingent of presenters including John A. Nevin, Allen Neuringer, Peter Killeen, and B.F. Skinner shared their thoughts and observations regarding these important issues. The papers that follow are based upon those presentations.

—A.J.M. Marcattilio 